\title{
Decreased expression level and DNA-binding activity of specificity protein 1 via cyclooxygenase-2 inhibition antagonizes radiation resistance, cell migration and invasion in radiation-resistant lung cancer cells
}

\author{
RUIJUN LIU, QIANG TAN and QINGQUAN LUO \\ Department of Shanghai Lung Cancer Center, Shanghai Chest Hospital, \\ Shanghai Jiao Tong University, Shanghai 200030, P.R. China
}

Received November 12, 2015; Accepted April 27, 2018

DOI: $10.3892 / \mathrm{ol} .2018 .9035$

\begin{abstract}
Radiation is able to inhibit tumor growth, promote tumor cell apoptosis and prolong patient survival. However, radiation resistance remains a major impediment to radiotherapy. Local and metastatic recurrences following radiation are still large impediments to overall survival. Although cyclooxygenase-2 (COX-2) inhibitors may induce radiation sensitivity in cancer cells, the underlying mechanisms are not fully understood. The present study demonstrated high potential for cell proliferation, migration and invasion in radiation-resistant lung cancer cell lines. The present study observed the overexpression of specificity protein 1 (Sp1) in these cells, and the overexpression of Spl induced upregulation of matrix metalloproteinase (MMP)-2, MMP-9, B cell lymphoma-2, in addition to a high potential for radiation resistance, migration and invasion in these cells. The present study revealed that the COX-2 selective inhibitor, celecoxib, enhanced radiation sensitivity and inhibited migration and invasion in these cells by inhibiting the expression and DNA-binding activity of Sp1. Furthermore, celecoxib downregulated Sp1 by inhibiting c-Jun N-terminal kinase (JNK). Taken together, the present study demonstrated that Spl overexpression in radiation-resistant cancer cells and COX-2 inhibitors enhanced radiation sensitivity and inhibited the migration and invasion of cancer cells, at least partially, via inactivation of the JNK/Sp1 signaling pathway and a decrease in Sp1 DNA-binding activity.
\end{abstract}

Correspondence to: Dr Qingquan Luo, Department of Shanghai Lung Cancer Center, Shanghai Chest Hospital, Shanghai Jiao Tong University, 241 Huaihaixi Road, Shanghai 200030, P.R. China E-mail: luoqq2001@sina.com

Key words: lung cancer, cyclooxygenase-2, radiation, specificity protein 1, c-Jun $\mathrm{N}$-terminal kinase

\section{Introduction}

Lung cancer is one of the leading causes of mortality and morbidity globally, and is one of the types of cancer with the lowest survival rates $(1,2)$. Lung cancer has a poor prognosis with a 5 -year survival rate of $<15 \%$ (3). Although novel therapeutic strategies have emerged $(4,5)$, radiotherapy is still one of the most effective treatments for lung cancer $(6,7)$.

As an important treatment for cancer, radiation may inhibit tumor growth, promote tumor cell apoptosis and prolong patient survival time; however, local or metastatic recurrences remain impediments to overall survival $(8,9)$. Additionally, radiation resistance is another obstacle for radiotherapy (10). Radiation activates a number of signals, including nuclear factor- $\mathrm{\kappa B}$ and signal transducer and activator of transcription 3 to induce radiation resistance $(11,12)$. Furthermore, it has been reported that radiation may promote cancer metastasis; for example, Guerra et al demonstrated that irradiated patients developed a higher rate of invasive recurrences compared with non-irradiated patients (13). Additionally, previous studies have revealed that radiation promotes the invasion and migration of numerous tumor cells, including glioma cells (14), hepatocellular cancer cells (15) and breast cancer cells (16). Radiation is reported to induce invasion by upregulating matrix metalloproteinases (MMPs) in pancreatic cancer cells (17) and glioblastoma cells (14). Therefore, effective strategies are required to increase radiation sensitivity in cancer cells and intercept radiation-induced cell migration and invasion. However, the underlying mechanisms of radiation resistance and radiation-induced cell migration and invasion are not fully understood.

Specificity protein $1(\mathrm{Sp} 1)$ is a ubiquitously-expressed transcription factor that is overexpressed in a number of cancer subtypes (18-20). Sp1 is involved in cell proliferation (21), cell migration and invasion (18) and apoptosis (22). Sp1 is reported to regulate target gene transcription by binding to the GC-rich sequence in the promoter region (23). Numerous mechanisms have been reported to regulate the DNA binding of Sp1 $(24,25)$. For example, cyclin-dependent kinase (CDK) II increases the DNA-binding activity of Spl by phosphorylating Sp1 at Ser59 (24) and CDKI decreases the DNA-binding activity of Sp1 by phosphorylating Sp1 at Thr739 (25). 
Cyclooxygenase-2 (COX-2) is an enzyme that converts arachidonic acid into prostaglandins (26). It is overexpressed in numerous tumors (27-29) and acts on a number of signaling pathways involved in cell proliferation, apoptosis, migration and invasion. Therefore, COX-2 is a potential target for cancer chemotherapy $(30,31)$.

The present study demonstrated that a COX-2 inhibitor, celecoxib, induced apoptosis as well as antagonized cell migration and invasion by inhibiting the expression level and DNA-binding ability of Sp1 in radiation-resistant lung cancer cells.

\section{Materials and methods}

Cell culture. NCl-H1650 cells, purchased from American Type Culture Collection (Manassas, VA, USA), were incubated in RPMI-1640 medium (Invitrogen; Thermo Fisher Scientific, Inc., Waltham, MA, USA) supplemented with $10 \%$ fetal bovine serum (FBS; Invitrogen; Thermo Fisher Scientific, Inc.) at $37^{\circ} \mathrm{C}$ in an atmosphere containing $5 \% \mathrm{CO}_{2}$.

Antibodies, reagents and small interfering (si)RNA. The MMP-2 (cat. no. 40994), MMP-9 (cat. no. 13667), t-JNK (cat. no. 9252), p-JNK (cat. no. 9255), anti-IgG antibodies (cat. no. 14708) were purchased from Cell Signaling Technology, Inc. (Danvers, MA, USA). The $\beta$-actin (sc-58673) and $\mathrm{B}$ cell lymphoma-2 (Bcl-2; sc-509) antibodies were purchased from Santa Cruz Biotechnology, Inc. (Dallas, TX, USA) and the Sp1 antibody was purchased from Merck KGaA (Darmstadt, Germany). Secondary rat antibody conjugated with horseradish peroxidase (cat. no. A0208) was purchased from Biyuntian Biotechnology (Biyuntian, Beijing, China). Celecoxib (cat. no. S1261) and anisomycin (cat. no. S7409) were purchased from Selleck Chemicals (Houston, TX, USA). The small interfering (si)RNA for Sp1, 5'-UGUAGAGUCUGC CAACUGACCUGUC-3', was purchased from Santa Cruz Biotechnology, Inc. The scramble siRNA, 5'-UAGUGCUUA CGCAGUUGCUAGACCC-3', was synthesized by Guangzhou RiboBio Co., Ltd. (Guangzhou, China).

siRNA transfection. NCL-H1650 or NCL-H1650R cells were plated into six-well plates at $1 \times 10 \%$ well. After the cells reached 95\% confluence, they were transfected with or $100 \mathrm{nmol}$ small interfering RNA (siRNA) using Lipofectamine ${ }^{\circledR} 2000$ (Invitrogen; Thermo Fisher Scientific, Inc.), according to the manufacturer's instructions. The cells were cultured in RPMI-1640 medium supplemented with $10 \% \mathrm{FBS}$ at $37^{\circ} \mathrm{C}$ in an atmosphere containing $5 \% \mathrm{CO}_{2}$. The cells were harvested $48 \mathrm{~h}$ after transfection.

Identification of radiation-resistant lung cancer cells. The $\mathrm{NCl}-\mathrm{H} 1650$ cells were exposed to $4 \mathrm{~Gy}$ 60Co radiation (dose rate was $2.5 \mathrm{~Gy} / \mathrm{min}$ ) and dead cells were removed every day until the surge of apoptosis had ceased, for one week. The remaining cells were then exposed to 4 Gy $60 \mathrm{Co}$ radiation again and any dead cells were removed. The aforementioned procedures were repeated until there was no apoptosis surge observed following exposure to radiation. The duration of this total process was $\sim 3$ months. The radiation-resistant cells were subsequently referred to as $\mathrm{NCl}-\mathrm{H} 1650 \mathrm{R}$ cells.
Treatment with radiation. NCL-H1650 cells and NCL-H1650R cells were seeded in 6-well plates at $5 \times 10^{4} /$ well and cultured in RPMI-1640 medium supplemented with $10 \% \mathrm{FBS}$ at $37^{\circ} \mathrm{C}$ in an atmosphere containing $5 \% \mathrm{CO}_{2}$. After $24 \mathrm{~h}$, both cell types were treated with $8 \mathrm{~Gy} 60 \mathrm{Co}$. The cells were cultured for another $24 \mathrm{~h}$ at $37^{\circ} \mathrm{C}, 5 \% \mathrm{CO}_{2}$; the cell proliferation apoptosis was detected.

Treatment with celecoxib, SP600125 or anisomycin. Celecoxib was diluted in dimethyl sulfoxide (DMSO; Sigma-Aldrich; Merck KGaA, Darmstadt, Germany) to produce 0, 20, 40 and $80 \mu$ M dilutions of celecoxib. SP600125 (Sigma-Aldrich; Merck $\mathrm{KGaA}$ ) was diluted in DMSO (Sigma-Aldrich; Merck KGaA) to make a $20 \mu \mathrm{M}$ SP600125. Anisomycin (Sigma-Aldrich; Merck KGaA) was diluted in DMSO (Sigma-Aldrich; Merck $\mathrm{KGaA}$ ) to make a $20 \mathrm{nM}$ dilution. NCL-H1650 cells and NCL-H1650R cells were seeded in 6-well plates at 5x104/well and cultured in RPMI-1640 medium supplemented with $10 \%$ FBS at $37^{\circ} \mathrm{C}$ in an atmosphere containing $5 \% \mathrm{CO}_{2}$. After the cells were cultured for $24 \mathrm{~h}$, celecoxib, SP 600125, anisomycin or the vehicle of DMSO were added. The cells were cultured for another $24 \mathrm{~h}$ at $37^{\circ} \mathrm{C}, 5 \% \mathrm{CO}_{2}$. The cells were then subject to other treatments, including protein extraction or $60 \mathrm{Co}$ exposure as described below.

Assessment of cell apoptosis. NCL-H1650 and NCL-H1650R cells were washed with PBS three times and then fixed with 95\% ethanol for $5 \mathrm{~min}$ at room temperature and stained with $5 \mathrm{mg} / \mathrm{ml}$ DAPI for $3 \mathrm{~min}$ at room temperature. The cells were then washed with PBS and examined under a fluorescence microscope (magnification, x20, Nikon Corporation, Tokyo, Japan) at a wavelength of $385 \mathrm{~nm}$. The cells with nuclear condensation and fragmentation were identified as apoptotic cells. The apoptotic cells were counted within five randomly selected fields. The rate of apoptotic cells was presented as the mean \pm standard deviation (SD).

Transwell assays. For migration assays, NCL-H1650 and NCL-H1650R cells were seeded in the upper chambers at $10^{5}$ cells/well in serum-free RPMI-1640 medium, while the lower chambers contained the culture medium supplemented with $10 \%$ FBS. The cells were incubated for $12 \mathrm{~h}$ at $37^{\circ} \mathrm{C}$ in an atmosphere containing $5 \% \mathrm{CO}_{2}$. Subsequently, the cells on the top surface of the membrane were removed and the cells on the bottom surface of the membrane were fixed with $4 \%$ paraformaldehyde for $10 \mathrm{~min}$ and stained with $0.01 \%$ crystal violet for $5 \mathrm{~min}$ at room temperature. The cells on the bottom surface of the membrane were then examined under a light microscope (Nikon Corporation), counted and averaged by the number within six randomly selected fields, magnification, x20. For the Transwell invasion assay, the upper chambers were coated with $20 \mu \mathrm{g}$ Matrigel (Sigma-Aldrich; Merck KGaA) to seeding of the NCL-H1650 and NCL-H1650R cells. The medium used and the time and temperature of incubation were the same as the migration assay.

Western blotting. Cells were lysed with the RIPA lysis buffer (Merck $\mathrm{KGaA}$ ) at room temperature for $30 \mathrm{~min}$, and then the lysates were centrifuged at $12,000 \times \mathrm{g} 4^{\circ} \mathrm{C}$ for $30 \mathrm{~min}$. Following centrifugation, the supernatant was collected. Protein concentrations were evaluated by BCA protein assay. Subsequently, 
$20 \mu \mathrm{g}$ protein per lane was used for $10 \%$ SDS-PAGE electrophoresis and transferred onto a nitrocellulose membrane (Merck KGaA). The membrane was blocked with 5\% fat-free milk in TBS Tween 20 (TBST) for $1 \mathrm{~h}$ at room temperature and then incubated with primary antibodies $(1: 1,000$ diluted in $5 \%$ fat-free milk) for $16 \mathrm{~h}$ at $4^{\circ} \mathrm{C}$. The membrane was washed with TBST three times and then incubated with secondary goat anti-rat $\mathrm{IgG}$ antibody conjugated with horseradish peroxidase (1:10,000 diluted in TBST) for $1 \mathrm{~h}$ at room temperature. Following washing with TBST, the membrane was visualized with Beyo ECL plus reagents (Biyuntian, Beijing, China). Protein expression levels were quantified with Image J 1.48 software (National Institutes of Health, Bethesda, MD, USA). Data were presented as the mean \pm SD of three independent experiments.

Chromatin immunoprecipitation assay (ChIP). The ChIP assay was performed using a ChIP assay kit (Upstate Biotechnology, Inc., Lake Placid, NY, USA). Briefly, NCl-H1650R cells were cross-linked with $1 \%$ formaldehyde at room temperature for $10 \mathrm{~min}$. The chromatin was sonicated into fragments ranging between 200-1,000 base pairs using an Ultrasonic Processor (Toshiba Corporation, Tokyo, Japan) at $4^{\circ} \mathrm{C}$ for $10 \mathrm{~min}$ and was subsequently pulled down using Sp1 antibodies or the anti-IgG antibody, which were 1:100 diluted in SDS lysis buffer (Beijing Pulilai Gene Technology Co., Ltd., Beijing, China) at room temperature for $1 \mathrm{~h}$. Then the polymerase chain reaction (PCR) amplification was performed to detect the binding DNA fragment. DNA polymerase was purchased form Promega Corporation (Madison, WI, USA) The primers used for amplifying the fragments of the MMP-2 promoter containing the Sp1-binding site were adopted from a previous study (32) and were as follows: Sense, 5'-GTCCTGGCAATCCCTTTG-3' and antisense, 5'-GGGGAAAAGAGGTGGAGAAA-3'. PCR reaction step was as follows: Initial denaturation $\left(95^{\circ} \mathrm{C}, 5 \mathrm{~min}\right)$; and Reaction [denaturation $\left(95^{\circ} \mathrm{C}, 1 \mathrm{~min}\right)$, annealing $\left(55^{\circ} \mathrm{C}\right.$, $1 \mathrm{~min})$, extension $\left.\left(72^{\circ} \mathrm{C}, 30 \mathrm{sec}\right)\right]$ for 30 cycles). PCR reaction was performed in Eppendorf Mastercycler nexus (Eppendorf, Hamburg, Germany). The PCR products were analyzed on $1.5 \%$ agarose gel. The densitometry of the bands was evaluated with Image J 1.48 software. Data were presented as the mean \pm SD of three independent experiments.

Statistical analysis. Statistical analysis was performed using SPSS v11.5 for Windows (SPSS, Inc., Chicago, IL, USA). All data were presented as the mean \pm SD. The intergroup comparison was performed by using single-factor analysis of variance. $\mathrm{P}<0.05$ was considered to indicate a statistically significant difference.

\section{Results}

Radiation-resistant lung cancer cells revealed high potential for radiation resistance, cell migration and cell invasion. The present study we selected radiation-resistant cells from the NCl-H1650 cell lines using discontinuous 4 Gy 60Co, referred to as NCl-H1650R. To investigate whether NCL-H1650R cells were more resistant than NCL-H1650 cells, NCl-H1650 cells and NCL-H1650R cells were exposed to radiation (8 Gy60Co) and subsequently cultured for $24 \mathrm{~h}$. Radiation significantly induced apoptosis and inhibited cell proliferation in NCl-H1650 cells; however, NCl-H1650R cells demonstrated only slight induction of apoptosis and inhibition of cell proliferation (Fig. 1A and B). The present study further investigated whether migration and invasion differed in NCl-H1650R cells compared with their parental cells. As presented in Fig. 1C, $\mathrm{NCl}-\mathrm{H} 1650 \mathrm{R}$ cells had higher migration and invasion abilities compared with NCl-H1650 cells.

COX-2 selective inhibitor celecoxib induced apoptosis and inhibition of cell migration and invasion in radiation-resistant lung cancer cells. COX-2 inhibitors have previously been reported to induce radiation sensitivity (33); therefore, the present study investigated whether the COX-2 inhibitor, celecoxib, induced radiation sensitivity and inhibited cell migration and invasion in radiation-resistant cells. $\mathrm{NCl}-\mathrm{H} 1650 \mathrm{R}$ cells were treated with celecoxib, which were subsequently exposed to 8 Gy60Co radiation and then cultured for $24 \mathrm{~h}$. Celecoxib inhibited cell proliferation and induced apoptosis in NCl-H1650R cells (Fig. 2A). Furthermore, when treated with celecoxib and radiation, these cells revealed significantly higher rates of apoptosis compared with the other groups. The present study also observed that celecoxib treatment significantly inhibited NCl-H1650R cell migration and invasion (Fig. 2B).

Spl overexpression was responsible for radiation resistance and the high potential of cell migration and invasion in radiation-resistant lung cancer cells. It has previously been reported that Sp1 was involved in numerous cell processes, including cell proliferation (21), migration and invasion (18) and apoptosis (22), thus the present study investigated whether Sp1was responsible for radiation resistance and the increased cell migration and invasion in radiation-resistant lung cancer cells. As presented in Fig. 3A, Sp1 was overexpressed in NC1-H1650R cells compared with NC1-H1650 cells, and this was associated with an upregulation of MMP-2, MMP-9 and Bcl-2 compared with NCl-H1650 cells. Subsequently, the present study knocked-down Sp1 in NCl-H1650R cells with Sp1 siRNA. Knockdown of Sp1 resulted in the downregulation of MMP-2, MMP-9 and Bcl-2 (Fig. 3B). Furthermore, a combination of the knockdown of $\mathrm{Spl}$ and radiation exposure significantly induced cell apoptosis in NCl-H1650R cells (Fig. 3C). Additionally, the present study revealed that the knockdown of Spl inhibited cell migration and invasion in NCl-H1650R cells (Fig. 3D).

Celecoxib inhibited expression and DNA-binding of $\mathrm{Spl}$. In order to confirm whether $\mathrm{Sp1}$ was responsible for celecoxib-induced cell apoptosis and inhibition of cell migration and invasion in radiation-resistant cancer cells, the present study treated NCl-H1650R cells with celecoxib. Sp1 was downregulated following celecoxib treatment, and this was associated with a corresponding downregulation of MMP-2, MMP-9 and Bcl-2 (Fig. 4A). As c-Jun N-terminal kinase (JNK) has been demonstrated to increase Sp1 protein stability, the inhibition of JNK may decrease E-Ras-induced Sp1 phosphorylation, and therefore decrease the protein stability of Spl (34). The present study hypothesized that the JNK signaling pathway mediated the celecoxib-induced 
A
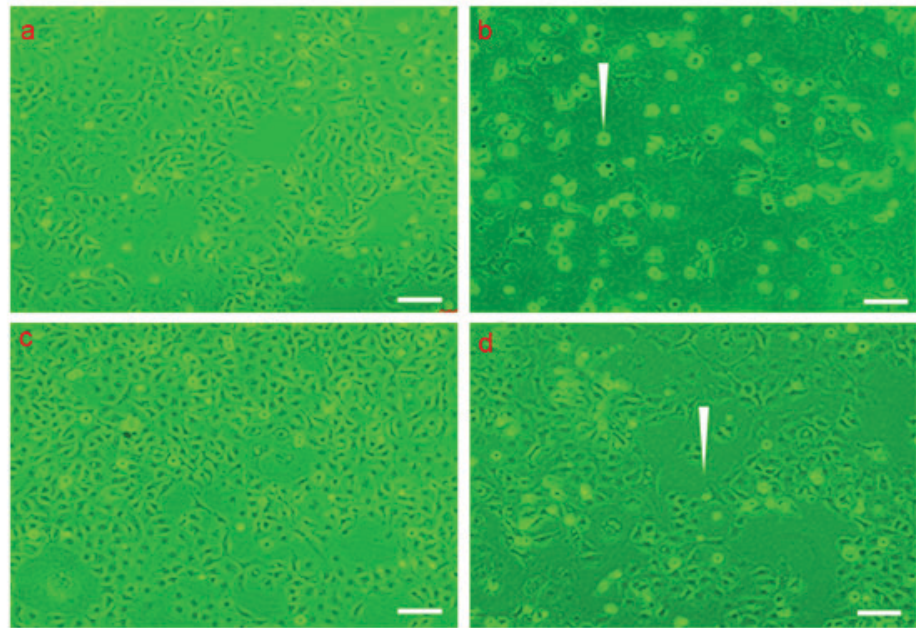
a, $\mathrm{NCl}-\mathrm{H} 1650 \mathrm{R}$ cells;
b, $\mathrm{NCl}-\mathrm{H} 1650 \mathrm{R}$ cells with 8 Gy radiation;
c, NCl-H1650R cells;
d, $\mathrm{NCl}-\mathrm{H} 1650 \mathrm{R}$ cells with $8 \mathrm{~Gy}$ radiation.

B
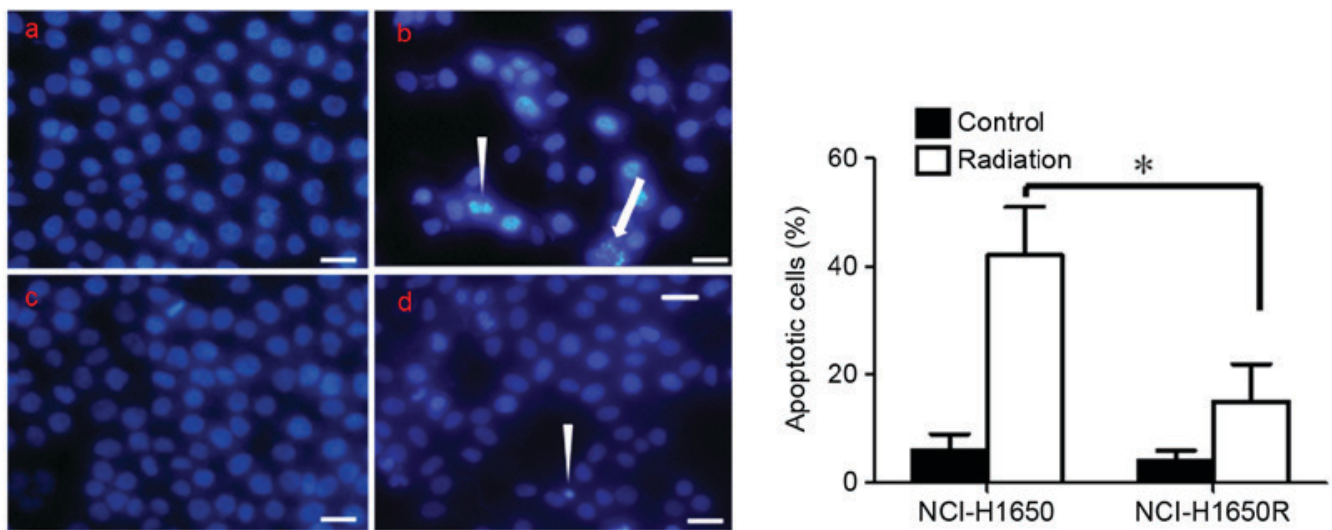

a, NCl-H1650R cells; b, NCl-H1650R cells with 8 Gy radiation; c,NCl-H1650R cells; d, NCl-H1650R cells with 8 Gy radiation.

C
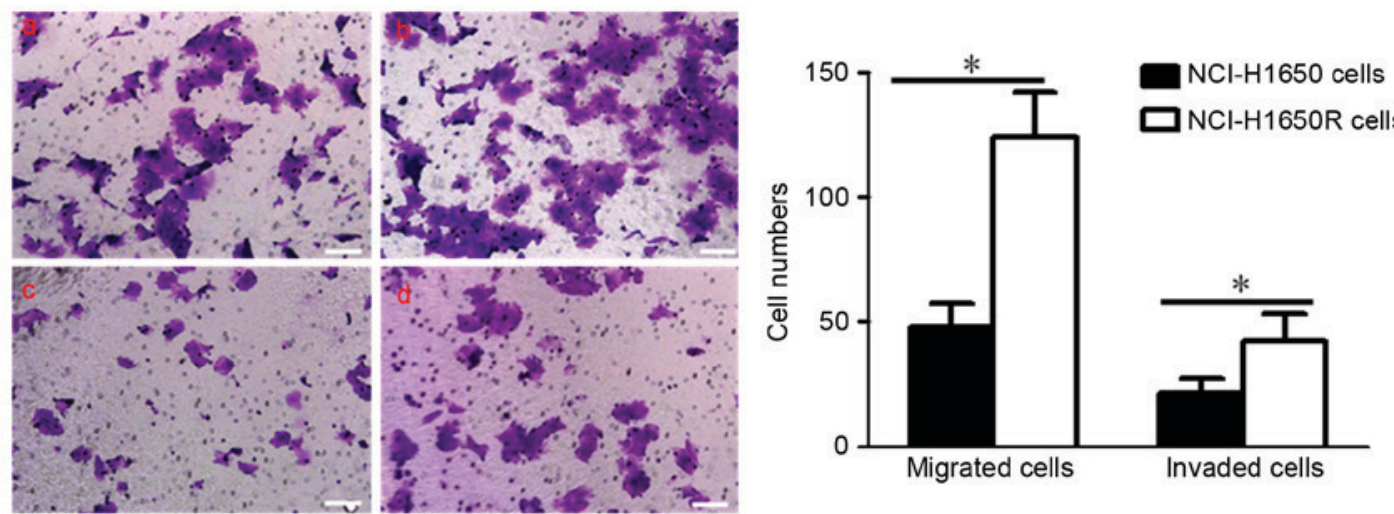

a, $\mathrm{NCl}-\mathrm{H} 1650$ migration;

b, NCl-H1650R migration;

c, $\mathrm{NCl}-\mathrm{H} 1650$ invasion;

d, $\mathrm{NCl}-\mathrm{H} 1650 \mathrm{R}$ invasion

Figure 1. Radiation-resistant lung cancer cells demonstrate high levels of cell migration and invasion. (A) Photomicrographs of cells following the stated treatments. Apoptotic cells are shrunken and floating, indicated by the triangle. Scale bars: $50 \mu \mathrm{m}$. (B) Fluorescent photomicrographs of cells following the indicated treatments. Cells were stained with DAPI following various treatments and those with nuclear condensation (triangle) or fragmentation (arrows) are identified as apoptotic cells. The right panel presents the apoptotic rate of cells following various treatments. Scale bars: $20 \mu \mathrm{m}$. (C) Photomicrographs of Transwell migrated or invaded radiation resistant and non-resistant NCL-H1650 cells, as indicated. Cell count of migrated or invaded cells from 6-10 separated fields is presented on the right. Scale bars: $20 \mu \mathrm{m}$. The data are presented as the mean \pm standard deviation. ${ }^{*} \mathrm{P}<0.05 \mathrm{vs}$. control or NCI-H1650 cells NCI-H1650R, radiation resistant NCI-H1650 cells. 
A
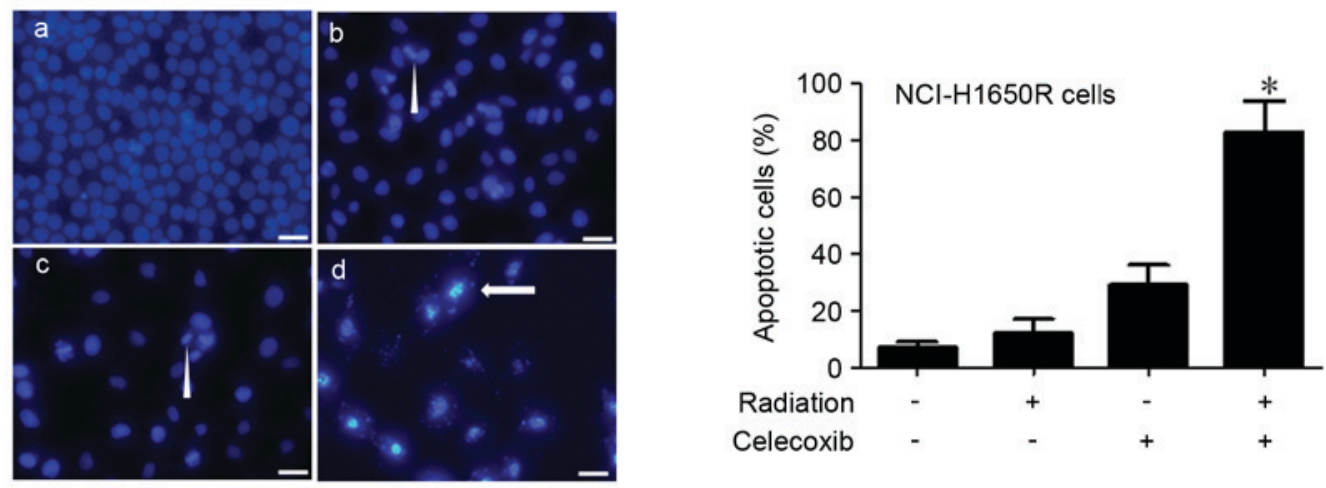

a, control; b, radiation; c, celecoxib; d, radiation+celecoxib

B

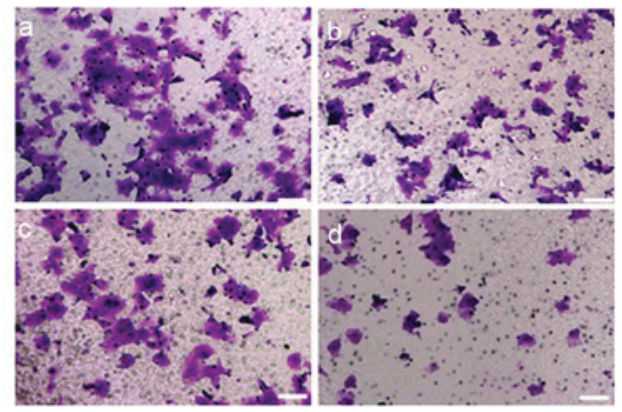

a, migration, control: $b$, migration, celecoxib c,invasion, control; $\quad d$, invasion, celecoxib

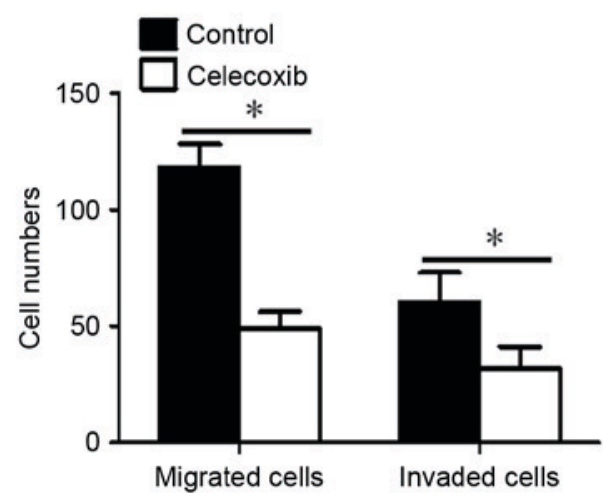

Figure 2. Celecoxib-induced apoptosis and inhibition of cell migration and invasion in radiation-resistant lung cancer cells. (A) The left panel presents fluorescent photomicrographs of NCL-H1650R cells following the indicated treatments. The cells were stained with DAPI, and cells with nuclear condensation (triangle) or fragmentation (arrows) were identified as apoptotic cells. The right panel presents the apoptotic rate of cells following the treatments. Scale bars: $20 \mu \mathrm{m}$. (B) Photomicrographs of migrated or invaded NCL-H1650R cells following the indicated treatments, as assessed by Transwell assay. The cell count of migrated or invaded cells from six separated fields is presented on the right. The data are presented as the mean \pm standard deviation. Scale bars: $20 \mu \mathrm{m}$. ${ }^{*} \mathrm{P}<0.05$ vs. control. NCL-H1650R, radiation resistant NCI-H1650 cells.

downregulation of $\mathrm{Sp} 1$. The present study detected the activation of JNK in radiation resistant NC1-H1650R cells and their parental NC1-H1650 cells. NCL-H1650 cells and NCL-H1650R cells were exposed to 8 Gy60Co radiation and then cultured for $24 \mathrm{~h}$. As presented in Fig. 4B, there was no change in the level of JNK phosphorylation, although Sp1 was overexpressed in NCl-H1650R cells compared with their parental cells. However, inhibition of the phosphorylation of JNK by the JNK inhibitor, SP600125, downregulated Sp1 in NCl-H1650R cells (Fig. 4C). Celecoxib was revealed to inhibit JNK phosphorylation, whereas the activation of JNK by anisomycin (that induced JNK phosphorylation by activating mitogen-activated protein kinase kinase) was able to reverse celecoxib-induced inhibition of JNK phosphorylation, Sp1 downregulation and the corresponding changes of MMP-2, MMP-9 and Bcl-2 (Fig. 4D). These results indicated that JNK was involved in celecoxib-induced $\mathrm{Sp} 1$ downregulation, radiation sensitivity, inhibition of cell migration and invasion.

As a transcription factor, the transcription activity of Sp1 depends on its DNA binding ability, thus the present study performed a ChIP assay on NCl-H1650R cells using primers to amplify the region in the MMP-2 promoter containing the Sp1 binding site, in order to determine whether celecoxib treatment altered Sp1 binding to the MMP-2 promoter. As presented in Fig. 4E, specific DNA fragment was amplified from the chromatin pulled down by the anti-Sp1 antibody (but not by the anti-IgG antibody) and this pulled-down fragment was decreased following celecoxib treatment. These results indicated that the COX-2 selective inhibitor inhibited Sp1 DNA-binding activity.

\section{Discussion}

The present study demonstrated that the COX-2 selective inhibitor, celecoxib, induced cell apoptosis and the inhibition of cell migration and invasion via the JNK/Sp1 signaling pathway. The results of the present study provide novel evidence that radiation-resistant cells may contribute to local or metastatic recurrence, and that celecoxib maybe used to enhance the radiation sensitivity of cancer cells and inhibit cell migration and invasion.

Radiation-resistant cancer cells are more capable of surviving radiation and have a high potential for proliferation, migration and invasion. Radiation is an effective treatment for cancer; however, local or metastatic recurrences remain common outcomes (13). Therefore, radiation resistance and radiation-induced migration and invasion have attracted increasing attention (14-16,35). The present study established one radiation-resistant lung cancer cell line from NCl-H1650 cells. Notably, a subpopulation of radiation-resistant cells 
A
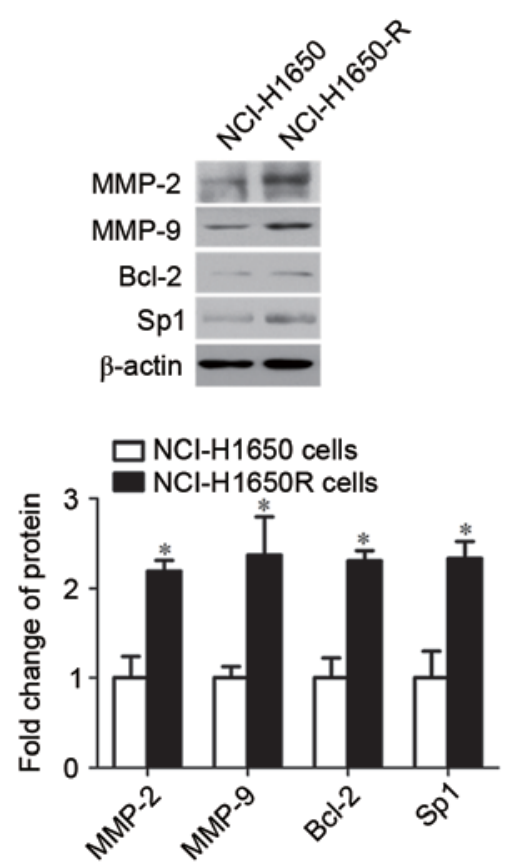

C
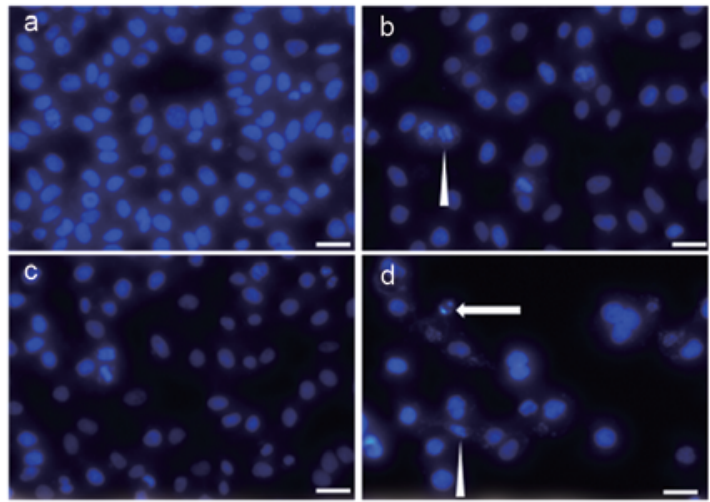

a,control; b,radiation;

c,Sp1 siRNA; d, radiation+Sp1 siRNA

D

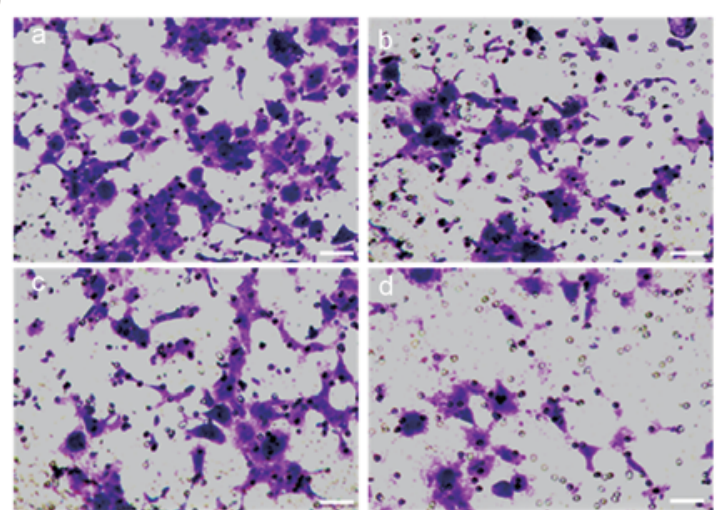

B
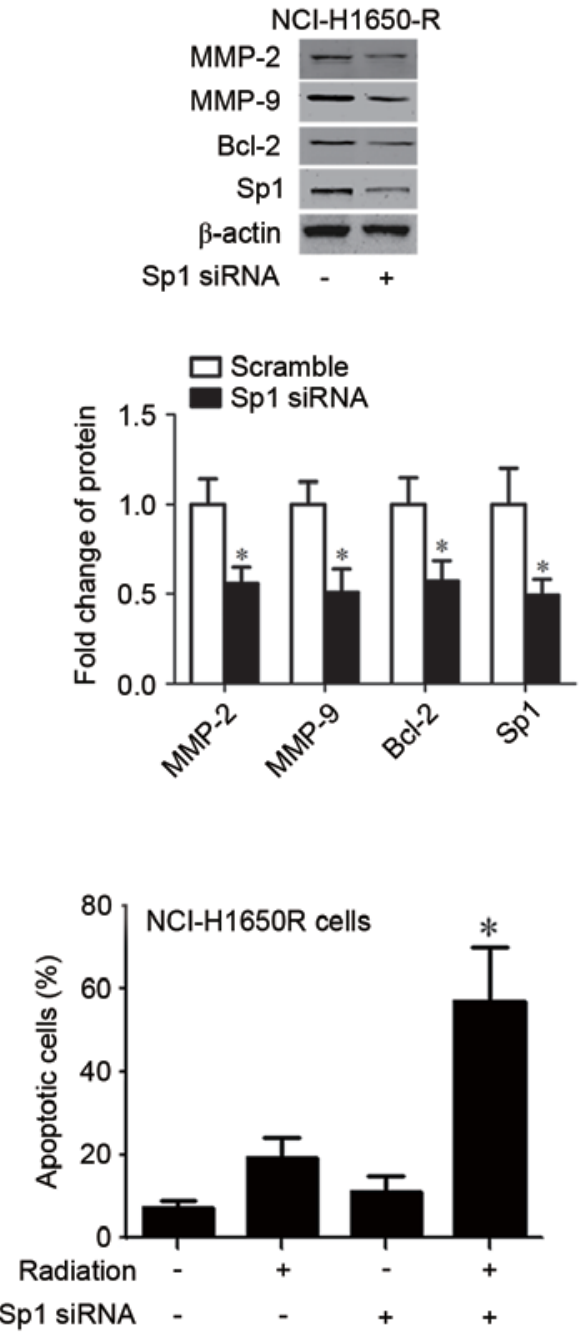

a, migration, control; b, migration, Sp1 siRNA

c, invasion, control; d, invasion, Sp1 siRNA

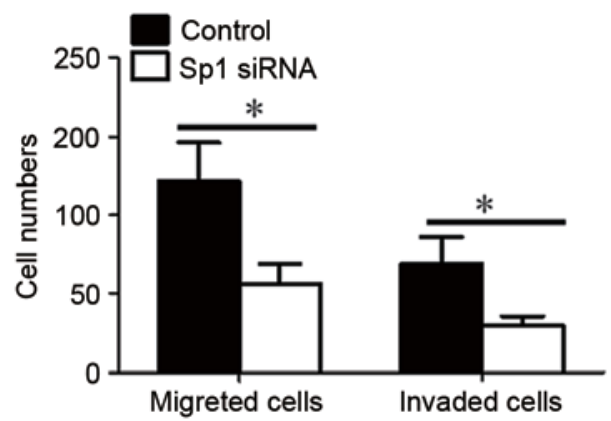

Figure 3. Sp1 was overexpressed in and responsible for radiation resistance and increased cell migration and invasion in radiation-resistant cancer cells. Protein expression levels of Sp1, MMP2, MMP9 and Bcl-2 were determined by western blotting in (A) NCL-H1650 and NCL-H1650R cells, and (B) NCL-H1650R cells transfected with control or Sp1 siRNA. $\beta$-actin served as an internal control. (C) The left panel presents fluorescent photomicrographs of NCL-H1650R cells. The cells were stained with DAPI following the indicated treatments and those cells with nuclear condensation (triangle) or fragmentation (arrows) were identified as apoptotic cells. Scale bars: $20 \mu \mathrm{m}$. The right panel presents the apoptotic rate of cells following various treatments. (D) Photomicrographs of migrated or invaded NCL-H1650R cells following the indicated treatments, as assessed by Transwell assay. The cell counts of migrated or invaded cells from 6-10 separate fields are presented on the right. The data are presented as the mean \pm standard deviation. Scale bars: $20 \mu \mathrm{m}$. ${ }^{*} \mathrm{P}<0.05$ vs. NCI-H1650 cells, scramble siRNA or control. Sp1, specificity protein 1; MMP, matrix metalloproteinase; Bcl-2, B cell lymphoma-2; NCL-H1650R, radiation resistant NCI-H1650 cells; siRNA, short interfering RNA. 
A

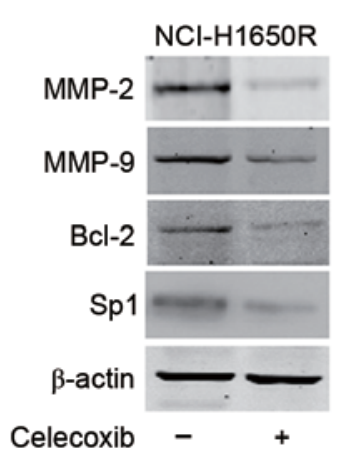

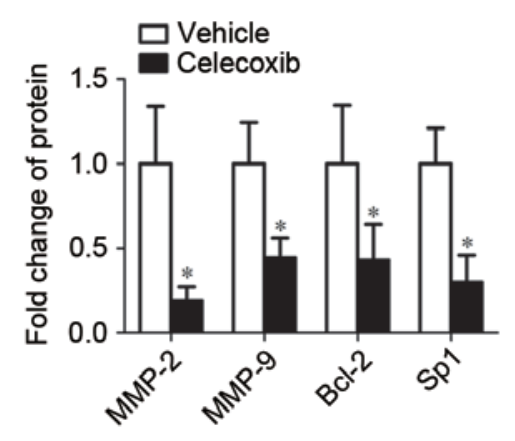

B

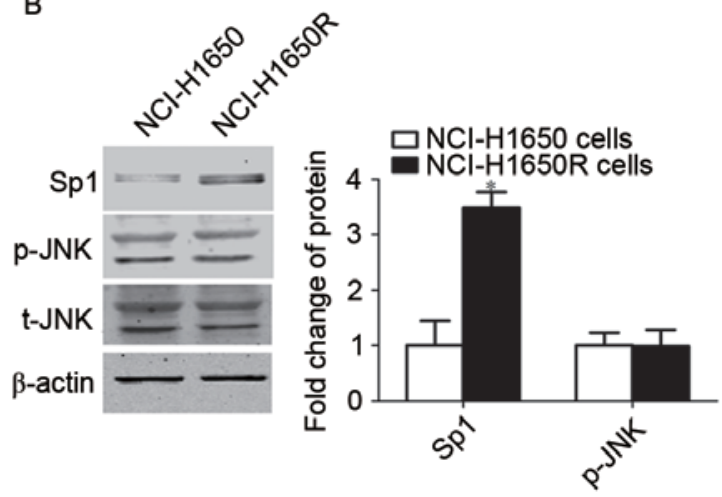

C
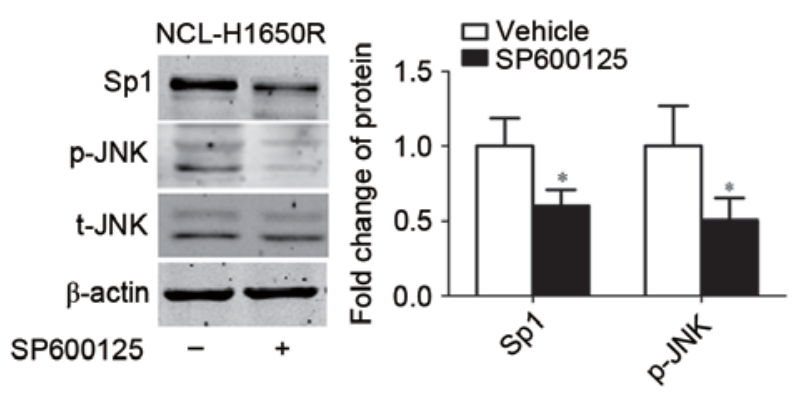

D

E

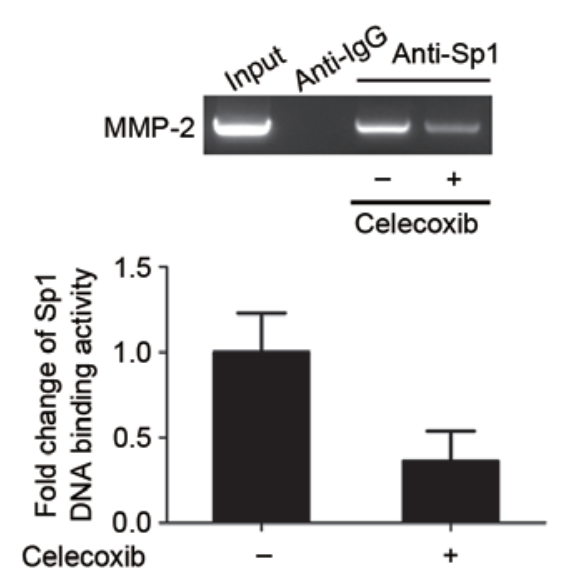

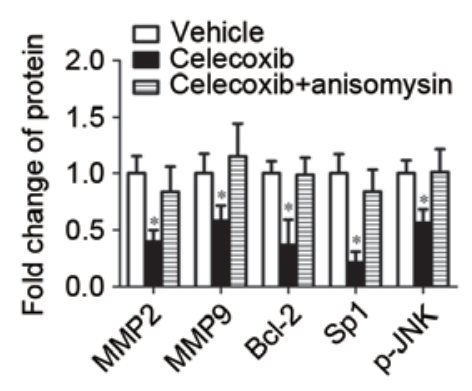

Figure 4. Celecoxib inhibited the expression and DNA-binding of Sp1. (A) Protein expression levels of Sp1, MMP2, MMP9 and Bcl-2 were determined by western blotting following celecoxib treatment. $\beta$-actin served as an internal control. Protein expression levels of t-JNK, p-JNK and Sp1 in (B) NCL-H1650 and NCL-H1650R cells and (C) NCL-H1650R cells treated with SP600125 or vehicle. " $\mathrm{P}<0.05$ vs. vehicle group. (D) Protein expression levels of t-JNK, p-JNK, Sp1, MMP2, MMP9 and Bcl-2 following treatment with celecoxib and/or anisomycin. " $\mathrm{P}<0.05$ vs. vehicle group. (E) Chromatin immunoprecipitation assays were performed in NCL-H1650R cells with anti-Sp1 or anti-IgG antibodies, using primers to amplify the region of the MMP-2 promoter containing the Spl-binding site. Sp1, specificity protein 1; MMP, matrix metalloproteinase; Bcl-2, B cell lymphoma-2; JNK, c-Jun N-terminal kinase; $t$, total; p, phosphorylated; NCL-H1650R, radiation resistant NCI-H1650 cells.

already exists in a number of cell lines, including the MCF-7/C6 breast cancer cell line (36) and the nasopharyngeal carcinoma CNE-2 cell line (37), and these radiation-resistant cancer cells are responsible for cancer recurrence following radiotherapy, including local or metastatic recurrence. The present study revealed that these radiation-resistant cancer cells were not only resistant to radiation, but also exhibited increased cell migration and invasion compared with non-resistant cells, which may be the reason local or metastasis recurrences occur. As a result, these radiation-resistant cancer cells have become a target for decreasing local or metastatic cancer recurrence.

The overexpression of $\mathrm{Spl}$ was responsible for increased levels of radiation resistance, cell migration and invasion irradiation-resistant lung cancer cells. The results of the present study revealed that $\mathrm{Sp} 1$ was overexpressed in radiation-resistant cancer cells, with a corresponding upregulation of MMPs and Bcl-2. Knockdown of Sp1 inhibited cell proliferation, migration and invasion. These results were consistent with numerous previous studies that demonstrated that Sp1 promoted cell proliferation, migration and invasion by regulating MMPs and Bcl-2 (38-40). To the best of our knowledge, this is the first study to reveal that $\mathrm{Sp1}$ is responsible for radiation resistance and increased cell migration and invasion in radiation-resistant lung cancer cells. Drugs that downregulate or inactivate Sp1 may be used to antagonize cancer radiation resistance and metastasis following radiation treatment.

Celecoxib was demonstrated to enhance radiation sensitivity and decrease cell migration and invasion, at least 
partially, by antagonizing the Sp1-induced upregulation of MMPs and Bcl-2. The present study observed that celecoxib may significantly induce radiation sensitivity and inhibit cell migration and invasion of the radiation-resistant lung cancer cells. The present study also observed that celecoxib significantly reduced $\mathrm{Sp} 1$ expression and correspondingly downregulated MMP-2, MMP-9 and Bcl-2. Considering that $\mathrm{Sp} 1$ serves a crucial function in cancer cell progression, the results of the present study suggested that decreased Sp1 expression levels induced by the COX-2 inhibitor may have contributed to the antagonism of radiation-resistance and cell migration and invasion in radiation-resistant lung cancer cells. In addition to other previously reported mechanisms $(41,42)$, the induction of radiation sensitivity maybe another important underlying mechanism of COX-2 inhibitors. A phase II clinical study has previously revealed that celecoxib is able to improve the radiotherapy outcome of patients with rectal cancer (43). Therefore, the results of the present study further supported the suggestion that COX-2 inhibitors may be promising enhancers of tumor radiotherapy.

Celecoxib downregulated Sp1 by inactivating the JNK signaling pathway. It has been reported that the activation of JNK may increase Sp1 stability (44). The present study observed that the inactivation of JNK may downregulate Sp1 and that the activation of JNK by anisomycin may antagonize celecoxib-induced Sp1 downregulation and the corresponding changes to MMP-9, MMP-2 and Bcl-2 expression levels. Of note, the present study did not observe higher activation of JNK in radiation resistant lung cancer cells compared with their parental cells. This may be because JNK was not responsible for the overexpression of $\mathrm{Sp} 1$ in radiation-resistant lung cancer cells, but the inactivation of JNK following treatment with the COX-2 inhibitor did contribute to the downregulation of $\mathrm{Sp} 1$, increased radiation sensitivity and the inhibition of cell migration and invasion.

Celecoxib treatment decreased Sp1 DNA-binding activity. The transcription activity of $\mathrm{Spl}$ depends on its DNA-binding ability to the promoters of target genes $(32,38)$. The present study demonstrated that celecoxib decreased Sp1 DNA-binding activity to the MMP-2 promoters, indicating that celecoxib downregulated MMP-2 by decreasing the binding activity of Sp1 to the MMP-2 promoters, and may act via the same mechanism for MMP-9 and Bcl-2. A number of factors may affect Sp1 DNA-binding activity, including CDKII (24) and CDKI (25); however, the determination of which factor is involved in the celecoxib-induced decrease of Sp1 DNA-binding activity requires further investigation.

In conclusion, the present study revealed that $\mathrm{Sp1}$ was overexpressed in radiation-resistant lung cancer cells and that COX-2 inhibitors induced radiation sensitivity and decreased cell migration and invasion in radiation-resistant lung cancer cells via the inactivation of the JNK/Sp1 signaling pathway and a decrease in Sp1 DNA-binding activity. Based on these findings, COX-2 inhibitors may be used in combination with radiation therapy to enhance the radiation sensitivity of cancer cells and reduce cancer metastasis.

\section{Acknowledgements}

Not applicable.

\section{Funding}

No funding was received.

\section{Availability of data and materials}

All data generated or analyzed during this study are included in this published article.

\section{Authors' contributions}

RL cultured the cells, established the radio resistance cell line and treated the cells with celecoxib and radiation. QT conducted the transfection experiments and western blot assay. QL performed the CCK-8 cell proliferation assay and detected the cell apoptosis.

\section{Ethics approval and consent to participate}

Not applicable.

\section{Consent for publication}

Not applicable.

\section{Competing interests}

The authors declare that they have no competing interests.

\section{References}

1. Ferlay J, Parkin DM and Steliarova-Foucher E: Estimates of cancer incidence and mortality in Europe in 2008. Eur J Cancer 46: 765-781, 2010

2. Ferlay J, Shin HR, Bray F, Forman D, Mathers C and Parkin DM: Estimates of worldwide burden of cancer in 2008: GLOBOCAN 2008. Int J Cancer 127: 2893-2917, 2010.

3. Jemal A, Siegel R, Ward E, Murray T, Xu J, Smigal C and Thun MJ: Cancer statistics, 2006. CA Cancer J Clin 56: 106-130, 2006.

4. Guan Z, Yu X, Wang H, Wang H, Zhang J, Li G, Cao J and Teng L: Advances in the targeted therapy of liposarcoma. Onco Targets Ther 8: 125-136, 2015.

5. Duong CP, Yong CS, Kershaw MH, Slaney CY and Darcy PK: Cancer immunotherapy utilizing gene-modified T cells: From the bench to the clinic. Mol Immunol 67: 46-57, 2015.

6. Kong FM, Zhao J, Wang J and Faivre-Finn C: Radiation dose effect in locally advanced non-small cell lung cancer. J Thorac Dis 6: 336-347, 2014.

7. Brady LW, Kramer S, Levitt SH, Parker RG and Powers WE: Radiation oncology: Contributions of the United States in the last years of the 20th century. Radiology 219: 1-5, 2001.

8. Alamanda VK, Song Y, Shinohara E, Schwartz HS and Holt GE: Postoperative radiation boost does not improve local recurrence rates in extremity soft tissue sarcomas. J Med Imaging Radiat Oncol 58: 633-640, 2014.

9. Cao CN, Luo JW, Gao L, Xu GZ, Li SY and Xiao JP: Recurrence of nasopharyngeal carcinoma in the parotid region after definitive intensity-modulated radiotherapy. J Oral Maxillofac Surg 71: 1993-1997, 2013

10. Milas L, Raju U, Liao Z and Ajani J: Targeting molecular determinants of tumor chemo-radioresistance. Semin Oncol 32 (Suppl 9): S78-S81, 2005.

11. Brach MA, Gruss HJ, Kaisho T, Asano Y, Hirano T and Herrmann F: Ionizing radiation induces expression of interleukin 6 by human fibroblasts involving activation of nuclear factor-kappa B. J Biol Chem 268: 8466-8472, 1993.

12. Yin ZJ, Jin FG, Liu TG, Fu EQ, Xie YH and Sun RL: Overexpression of STAT3 potentiates growth, survival, and radioresistance of non-small-cell lung cancer (NSCLC) cells. J Surg Res 171: 675-683, 2011. 
13. Guerra LE, Smith RM, Kaminski A, Lagios MD and Silverstein MJ: Invasive local recurrence increased after radiation therapy for ductal carcinoma in situ. Am J Surg 196: 552-555, 2008.

14. Wild-Bode C, Weller M, Rimner A, Dichgans J and Wick W: Sublethal irradiation promotes migration and invasiveness of glioma cells: Implications for radiotherapy of human glioblastoma. Cancer Res 61: 2744-2750, 2001.

15. Cheng JC, Chou CH, Kuo ML and Hsieh CY: Radiation-enhanced hepatocellular carcinoma cell invasion with MMP-9 expression through PI3K/Akt/NF-kappaB signal transduction pathway. Oncogene 25: 7009-7018, 2006.

16. Paquette B, Baptiste C, Therriault H, Arguin G, Plouffe B and Lemay R: In vitro irradiation of basement membrane enhances the invasiveness of breast cancer cells. Br J Cancer 97: 1505-1512, 2007.

17. Qian LW, Mizumoto K, Urashima T, Nagai E, Maehara N, Sato N, Nakajima M and Tanaka M: Radiation-induced increase in invasive potential of human pancreatic cancer cells and its blockade by a matrix metalloproteinase inhibitor, CGS27023. Clin Cancer Res 8: 1223-1227, 2002.

18. Hsu TI, Wang MC, Chen SY, Yeh YM, Su WC, Chang WC and Hung JJ: Sp1 expression regulates lung tumor progression. Oncogene 31: 3973-3988, 2012.

19. Zannetti A, Del Vecchio S, Carriero MV, Fonti R, Franco P, Botti G, D'Aiuto G, Stoppelli MP and Salvatore M: Coordinate up-regulation of Sp1 DNA-binding activity and urokinase receptor expression in breast carcinoma. Cancer Res 60: 1546-1551, 2000.

20. Chiefari E, Brunetti A, Arturi F, Bidart JM, Russo D, Schlumberger M and Filetti S: Increased expression of AP2 and Sp1 transcription factors in human thyroid tumors: A role in NIS expression regulation? BMC Cancer 2: 35, 2002.

21. Zhang JP, Zhang H, Wang HB, Li YX, Liu GH, Xing S, Li MZ and Zeng MS: Down-regulation of Sp1 suppresses cell proliferation, clonogenicity and the expressions of stem cell markers in nasopharyngeal carcinoma. J Transl Med 12: 222, 2014.

22. Cho JJ, Chae JI, Yoon G, Kim KH, Cho JH, Cho SS, Cho YS and Shim JH: Licochalcone A, a natural chalconoid isolated from Glycyrrhiza inflata root, induces apoptosis via Sp1 and Sp1 regulatory proteins in oral squamous cell carcinoma. Int J Oncol 45: 667-674, 2014.

23. Dynan WS and Tjian R: The promoter-specific transcription factor Sp1 binds to upstream sequences in the SV40 early promoter. Cell 35: 79-87, 1983.

24. Fojas de Borja P, Collins NK, Du P, Azizkhan-Clifford J and Mudryj M: Cyclin A-CDK phosphorylates Sp1 and enhances Sp1-mediated transcription. EMBO J 20: 5737-5747, 2001.

25. Chuang JY, Wang SA, Yang WB, Yang HC, Hung CY, Su TP, Chang WC and Hung JJ: Sp1 phosphorylation by cyclin-dependent kinase 1/cyclin B1 represses its DNA-binding activity during mitosis in cancer cells. Oncogene 31: 4946-4959, 2012.

26. Yang HW: COX-2 regulation of prostaglandins in synaptic signaling. Sheng Li Ke Xue Jin Zhan 40: 317-320, 2009 (In Chinese).

27. Lim HY, Joo HJ, Choi JH, Yi JW, Yang MS, Cho DY, Kim HS, Nam DK, Lee KB and Kim HC: Increased expression of cyclooxygenase-2 protein in human gastric carcinoma. Clin Cancer Res 6: 519-525, 2000.

28. Tucker ON, Dannenberg AJ, Yang EK, Zhang F, Teng L, Daly JM, Soslow RA, Masferrer JL, Woerner BM, Koki AT and Fahey TJ III: Cyclooxygenase-2 expression is up-regulated in human pancreatic cancer. Cancer Res 59: 987-990, 1999.

29. Molina MA, Sitja-Arnau M, Lemoine MG, Frazier ML and Sinicrope FA: Increased cyclooxygenase-2 expression in human pancreatic carcinomas and cell lines: Growth inhibition by nonsteroidal anti-inflammatory drugs. Cancer Res 59: 4356-4362, 1999.
30. Brown JR and DuBois RN: Cyclooxygenase as a target in lung cancer. Clin Cancer Res 10: 4266s-4269s, 2004.

31. Pruthi RS, Derksen E and Gaston K: Cyclooxygenase-2 as a potential target in the prevention and treatment of genitourinary tumors: A review. J Urol 169: 2352-2359, 2003

32. Wang $\mathrm{CH}$, Chang $\mathrm{HC}$ and Hung WC: p16 inhibits matrix metalloproteinase-2 expression via suppression of Sp1-mediated gene transcription. J Cell Physiol 208: 246-252, 2006.

33. Meng Z and Gan YH: Activating PTEN by COX-2 inhibitors antagonizes radiation-induced AKT activation contributing to radiosensitization. Biochem Biophys Res Commun 460: 198-204, 2015.

34. Kwon YW, Jang S, Paek JS, Lee JW, Cho HJ, Yang HM and Kim HS: E-Ras improves the efficiency of reprogramming by facilitating cell cycle progression through JNK-Sp1 pathway. Stem Cell Res 15: 481-494, 2015.

35. Ohuchida K, Mizumoto K, Murakami M, Qian LW, Sato N, Nagai E, Matsumoto K, Nakamura T and Tanaka M: Radiation to stromal fibroblasts increases invasiveness of pancreatic cancer cells through tumor-stromal interactions. Cancer Res 64: 3215-3222, 2004.

36. Guo L, Xiao Y, Fan M, Li JJ and Wang Y: Profiling global kinome signatures of the radioresistant MCF-7/C6 breast cancer cells using MRM-based targeted proteomics. J Proteome Res 14: 193-201, 2015.

37. Peng G, Cao RB, Li YH, Zou ZW, Huang J and Ding Q: Alterations of cell cycle control proteins SHP1/2, p16, CDK4 and cyclin D1 in radioresistant nasopharyngeal carcinoma cells. Mol Med Rep 10: 1709-1716, 2014.

38. Kou XX, Hao T, Meng Z, Zhou YH and Gan YH: Acetylated Sp1 inhibits PTEN expression through binding to PTEN core promoter and recruitment of HDAC1 and promotes cancer cell migration and invasion. Carcinogenesis 34: 58-67, 2013.

39. Duan H, Heckman CA and Boxer LM: Histone deacetylase inhibitors down-regulate bcl-2 expression and induce apoptosis in $\mathrm{t}(14 ; 18)$ lymphomas. Mol Cell Biol 25: 1608-1619, 2005.

40. Qiu T, Zhou X, Wang J, Du Y, Xu J, Huang Z, Zhu W, Shu Y and Liu P: MiR-145, miR-133a and miR-133b inhibit proliferation, migration, invasion and cell cycle progression via targeting transcription factor Sp1 in gastric cancer. FEBS Lett 588: 1168-1177, 2014.

41. Yang MY, Lee HT, Chen CM, Shen CC and Ma HI: Celecoxib suppresses the phosphorylation of STAT3 protein and can enhance the radiosensitivity of medulloblastoma-derived cancer stem-like cells. Int J Mol Sci 15: 11013-11029, 2014.

42. Kim YM, Jeong IH and Pyo H: Celecoxib enhances the radiosensitizing effect of 7-hydroxystaurosporine (UCN-01) in human lung cancer cell lines. Int J Radiat Oncol Biol Phys 83: e399-e407, 2012.

43. Wang LW, Hsiao CF, Chen WT, Lee HH, Lin TC, Chen HC, Chen HH, Chien CR, Lin TY and Liu TW: Celecoxib plus chemoradiotherapy for locally advanced rectal cancer: A phase II TCOG study. J Surg Oncol 109: 580-585, 2014.

44. Chuang JY, Wang YT, Yeh SH, Liu YW, Chang WC and Hung JJ: Phosphorylation by c-Jun NH2-terminal kinase 1 regulates the stability of transcription factor Sp1 during mitosis. Mol Biol Cell 19: 1139-1151, 2008.

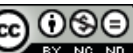

This work is licensed under a Creative Commons Attribution-NonCommercial-NoDerivatives 4.0 International (CC BY-NC-ND 4.0) License. 